\title{
Darbepoetin alpha in the treatment of cancer chemotherapy-induced anemia
}

\author{
Alberto Grossi' \\ Francesca Balestri² \\ Simone Santini ${ }^{3}$ \\ 'IstitutoLeonardo da Vinci - \\ Hematology, Florence, Italy; ${ }^{2}$ Blood \\ Transfusion Center, Azienda Sanitaria \\ 4, Prato, Italy; ${ }^{3}$ Oncology Unit, \\ Azienda Sanitaria 4, Prato, Italy
}

\begin{abstract}
Anemia is a common, but underestimated and undertreated, complication of patients with cancer receiving chemo- or radiotherapy, and negatively affects their quality of life (QoL). Erythropoietic proteins (EPS) offer an effective treatment of cancer anemia and ameliorate QoL, although their use requires the correct targeting of hemoglobin increase to avoid thromboembolic complications. Currently the effort is focused on offering patients this effective treatment with reduced frequency of administration. Higher weekly single doses of recombinant human Epo (rHuEpo) either alpha or beta, instead of three times per week, have been proposed for the treatment. The pharmacokinetic and pharmacodynamic characteristics of the hyperglycosylated protein darbepoetin alpha permit even longer intervals between administrations. Every other week or every three weeks schedules have shown results (erythropoietic response, reduction of transfusion requirements, and improvement of QoL) comparable with those of weekly rHuEpo.
\end{abstract}

Keywords: cancer anemia, recombinant human Epo, darbepoetin alpha

\section{Introduction}

Anemia is a frequent complication in patients with cancer and affects quality of life (QoL) (Cella 1997; Harper and Littlewood 2005) in at least 50\%. Correct investigation of the reasons underlying anemia is mandatory for an adequate treatment (Figure 1). A recent large survey (Ludwig et al 2004) has shown that prevalence and incidence were $39.3 \%$ of 14912 enrolled and $57.3 \%$ of 13628 analyzed patients respectively. Only $38.9 \%$ received a treatment of either transfusions or replacement therapy including recombinant human Epo ( $\mathrm{rHuEpo}$ ). Therefore an adequate treatment is not adopted in the majority patients with anemia of cancer.

A major step in the evaluation of anemia of chronic disorders, including cancer, was the recognition that erythropoietin production is often blunted and serum level inadequate to the degree of hemoglobin decrease because of toxicity, especially when platinum is used in therapy, or the disease itself (Figure 1). Therefore, the availability of rHuEpo alpha and beta, and successively darbepoetin alpha, has offered an effective alternative to red cell transfusion in this setting. Bohlius and colleagues (2005) carried out a metanalysis of 27 randomized controlled trials, involving 3953 patients, that compared the use of rHuEpo and darbepoetin (plus transfusion if needed) with observation until red blood cell transfusion was required. This study was recently updated (Bohlius et al 2006) to include 57 trials with 9353 patients. The analysis of data indicates that administration of EPS reduces the relative risk for blood transfusions and the number of units transfused in cancer patients. For patients with baseline hemoglobin below $12 \mathrm{~g} / \mathrm{dL}$ (mild anemia) there is strong evidence of improved hematological response and suggestive evidence of amelioration of QoL. On the other hand, the relative risk for thromboembolic complications increases by the treatment, while it remains uncertain whether and how rHuEpo and darbepoetin 


\section{Reduced BFU-E/CFU-E proliferation \\ (bone marrow infiltration; chemo-radiotherapy)}

\section{Reduced imon utilization; Functional iron deficiency}

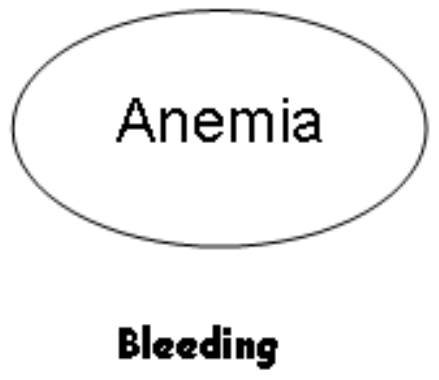

Blunted Epo production

Figure I Mechanism(s) of anemia in cancer patients

affect tumor response and overall survival. As for the disease outcome, the conclusion reflects the somewhat divergent results of a large randomized double blind versus placebo study suggesting a possible better outcome in patients treated with rHuEpo (Littlewood et al 2001), and those of two different studies that have shown a risk of worst outcome of cancer disease in patients treated with rHuEpo (Henke et al 2003; Leyland-Jones 2003). The expression of Epo receptor (EpoR) has been demonstrated on several nonerythroid tumor cells (Arcasoy et al 2005), but this does not invariably translate into the receptor activation. Moreover it has been shown that antibodies currently used in immunoblotting and immunostaining techniques lack specificity (Elliott et al 2006), therefore the results should be evaluated with caution.

American Society of Hematology/American Society of Clinical Oncology (ASCO) (Rizzo et al 2002), National Comprehensive Cancer Network (NCCN) (2006), and European Organisation for Research and Treatment of Cancer (EORTC) (Bokemeyer et al 2004) proposed guidelines for the use of erythropoietic proteins (EPS) in anemia of cancer. These indicate that scope of the treatment is not only the erythropoietic response (hemoglobin increase), but also the improvement of QoL, negatively affected by the anemia, and prevention of transfusion. The target hemoglobin level should be 12-13 g/ $\mathrm{dL}$ in order to reduce the risk of hypertension and thromboembolic events associated with this therapy (Bokemeyer et al 2004). However the efficacy of EPS relies on the presence of adequate iron availability for the necessity of erythropoiesis, therefore preliminary evaluation and monitoring of transferrin saturation are mandatory. If transferring saturation is $\leq 20 \%$ intravenous should be administered (Auerbach et al 2004)
The spectrum of EPS includes a large variety of products, such as erythropoietin delta (Deicher and Horl 2004) and omega (Bren et al 2002), with registration limited to anemia of kidney failure, while pegylated Epo beta (Osterborg et al 2004) and a pegylated synthetic peptide, Hematide (Stead et al 2006), are still under clinical evaluation. The only approved and currently marketed EPS for treatment of anemia in cancer patients are rHuEpo alpha and beta, and darbepoetin alpha. Data on rHuEpo are briefly mentioned in this review, which will focus especially on the activity of darbepoetin in the treatment of patients with cancer anemia.

\section{rHuEpo}

Treatment with EPS in the setting of anemia of chronic disorders, including cancer, requires higher doses (3- to 4fold) than in the treatment of anemia of kidney failure, due to the inhibition of endogenous Epo production, of bone marrow activity, or both. Therefore a typical schedule of $150 \mathrm{U} / \mathrm{Kg}(10000 \mathrm{U})$ of rHuEpo three times per week with rHuEpo alpha or beta is adopted in cancer patients instead of $40-50 \mathrm{ml} / \mathrm{Kg}$ used in chronic kidney failure. Response rate varies largely in relation to the disease. Commonly hemoglobin levels improve in $25 \%$ to $30 \%$ of patients with myelodysplastic syndrome (MDS) (Alessandrino et al. 2002), but in subgroups of patients with favourable characteristics (International Prognostic Scoring System [IPSS] low/intermediate 1 risk, reduced or no transfusion support, endogenous Epo levels $<200 \mathrm{mU} / \mathrm{ml}$ ) this rate can increasee to $50 \%$ with daily (ICSG 1998; Alessandrino et al 2002) or every other day (Terpos et al 2003) administrations of $10000 \mathrm{U}$. Hellstrom-Lindberg and colleagues (1998) demonstrated that the percentage of 
responders may increase if $\mathrm{rHuEpo}$ is used in combination with granulocyte-colony stimulating factor (G-CSF), a result recently confirmed by Balleari and colleagues (2005), and this protocol proved to be effective also in patients with higher endogenous Epo levels (up to $500 \mathrm{~m} \mathrm{U} / \mathrm{mL}$ ). In the MDS setting, it is particularly important to define correctly the criteria of response to evaluate the efficacy of treatment. A revised version has recently been published by the International Working Group (Cheson et al 2006). In patients with nonmyeloid malignancies, including non-Hodgkin lymphoma and multiple myeloma (MM), response is obtained in $50 \%$ to $70 \%$ of patients (Rizzo et al 2002), with the highest response rate in MM. Gabrilove and colleagues (2001) reported that a single weekly dose (QW) of rHuEpo alpha (40 000-60 000U) was as effective as the three times per week protocol, a result confirmed by others (Shasha et al 2003; Chang et al 2005; Witzig et al 2005). Similarly, QW dosing (30 000U) (Cazzola et al 2003) of rHuEpo beta are as effective as $10000 \mathrm{U}$ x 3 per week.

Henry and colleagues (2006) reported that a further extension of the interval between administration of rHuEpo alpha using $80000 \mathrm{U}$ Q2W was as effective as $40000 \mathrm{QW}$ with comparable safety.

Whether the measurement of endogenous Epo levels is a useful tool to predict the response in patients with solid cancer or lymphoproliferative disorders is questionable (Littlewood et al 2003; Ludwig et al 2004). These are inappropriately low in approximately $25 \%$ of all patients with MM, and increase to $50 \%$ in patients with stage III disease and $60 \%$ in those with renal impairment (Beguin et al 1992). Moreover, in some patients bone marrow infiltration participate to the poor response to $\mathrm{rHuEpo}$ (Beguin 1995).

In conclusion rHuEpo is convenient and effective treatment capable of reducing transfusion support, increasing hemoglobin level, and improving QoL.

\section{Darbepoetin alpha}

Darbepoetin alpha is a novel hyperglycosilated erythropoietic protein that, in comparison with $\mathrm{rHuEpo}$ alpha, contains $5 \mathrm{~N}$-linked carbohydrate chains versus 3 and 22 sialic acid residues versus 14 . These characteristics determine a 3 times longer half-life ( $25.3 \mathrm{~h}$ vs $8.45 \mathrm{~h})$, which increases in vivo biological activity in a murine model (Egrie and Browne 2001), and permits less frequent administrations. The roles of carbohydrate and sialic acid residues in determining the pharmacokinetics and pharmacodynamics of darbepoetin alpha have been elucidated by Elliot and colleagues (2004). Although less effective than rHuEpo in vitro in inducing colony-forming unit-erythroid proliferation (due to sialic acid residues), the longer half life confers an advantage in vivo, and the reduced affinity for EpoR further participates to maintain erythropoietic concentrations of darbepoetin over the time.

A QW administration of darbepoetin is sufficient for sustained stimulation of erythropoiesis. The percentage of cancer patients with hematopoietic response (hemoglobin $>2 \mathrm{~g} / \mathrm{dL}$ or $>12 \mathrm{~g} / \mathrm{dL}$ in the absence of red blood cell [RBC] transfusion) is dose-related, and time to hemoglobin response reduced compared with three times per week rHuEpo administration (Smith et al 2001; Glaspy et al 2002). Maximum concentration $\left(\mathrm{C}_{\max }\right)$ is reached at week 2 after chemotherapy, when the pool of erythroid cells is likely to be reduced as a consequence of chemotherapy (Heatherington et al 2001). This suggests that the clearance of darbepoetin is possibly due to binding to EpoR expressed on erythroid progenitor and precursor cells (Glaspy et al 2005). Finally, there is a trend toward increasing serum concentration of darbepoetin over time, as at cycle 3 concentration was doubled compared with cycle 1 . When tested in a randomized study versus placebo in patients with lung cancer (Vasteenkiste et al 2002), QW $150 \mu \mathrm{g}$ darbepoetin reduced transfusion support (27\% vs 52\%) and increased hematopoietic response (66\% vs 24\%). Similar results were reported by Hedenus and colleagues. (2003) in patients with non-Hodgkin lymphomas, and these authors observed a response to darbepoetin in $69 \%$ of patients with basal serum Epo $<100 \mathrm{mU} / \mathrm{mL}$ versus $44 \%$ in those with basal values $>100 \mathrm{mU} / \mathrm{mL}$. QoL also improved, as shown by a Functional Assessment of Cancer Therapy-Fatigue (FACT-F) score increased in $56 \%$ of patients treated with darbepoetin and $44 \%$ in the placebo group, although the difference was not significant. Recently Littlewood and colleagues (2006) confirmed the efficacy of darbepoetin in ameliorating fatigue and QoL in patients with lymphoproliferative disorders, in a multicenter randomized trial.

Currently in the QW schedule, darbepoetin is administered at the dose of $2.25 \mu \mathrm{g} / \mathrm{Kg}$ (150 mg fixed dose), to be increased to $4.50 \mu \mathrm{g} / \mathrm{Kg}(300 \mu \mathrm{g}$ fixed dose) if response is not observed at week four.

Darbepoetin $(150 \mu \mathrm{g}$ increased to $300 \mu \mathrm{g}$ if no response is observed) determines a substantial response also in patients with low-risk MDS (Musto et al 2005; Patton et al 2005) and may offer the advantage of less frequent administrations. In a recent series of 66 patients with low- 
intermediate 1 risk according to IPSS, Mannone and colleagues (2006) obtained an overall erythroid response of $71 \%$, comparable with that observed in patients treated with the rHuEpo alpha plus G-CSF combination.

\section{Darbepoetin every-other- week}

The pharmacokinetic characteristics of the Darbepoetin suggest that Q2W or longer intervals between administrations are made possible. In an open-label study, Vadhan-Raj and colleagues (2003) evaluated the ability of darbepoetin alpha to reverse chemotherapy-induced anemia in cancer patients, induce changes in fatigue and functional capacity and their relation to hemoglobin increase in patients with hemoglobin $\leq 11 \mathrm{~g} / \mathrm{dL}$ with nonmyeloid malignancy receiving multicycle chemotherapy. Darbepoetin alpha was administered at a starting dosage of $3 \mu \mathrm{g} / \mathrm{kg}$ Q2W for up to eight doses (16 weeks). The interim analysis included a total of 1174 patients: mean increase in hemoglobin was $1.7 \mathrm{~g}$ / dL (ITT analysis) and $2.1 \mathrm{~g} / \mathrm{dL}$ for those patients receiving the full 16 weeks of therapy. The Kaplan-Meier estimate of the proportion of subjects with a hematopoietic response (increase in hemoglobin $\geq 2 \mathrm{~g} / \mathrm{dL}$ and/or $\geq 12 \mathrm{~g} / \mathrm{dL}$ ) was $84 \%$. To summarize the results of this study: a) darbepoetin determined an hemoglobin response (greater in patients with hemoglobin $<10 \mathrm{~g} / \mathrm{dL}$ ) during treatment; b) the FACT-F subscale score increased by a mean of 6.8 points $(26 \%)$ during the study; c) improvements in fatigue score paralleled the increases observed in hemoglobin. In conclusion the efficacy of the Q2W regimen of darbepoetin alpha is no different from that of weekly or three times per week rHuEpo. Glaspy and colleagues (2002) tested the administration of darbepoetin in a randomized multi-arm study in which different doses of darbepoetin $(3 \mu \mathrm{g} / \mathrm{kg}, 5 \mu \mathrm{g} /$ $\mathrm{kg}, 7 \mu \mathrm{g} / \mathrm{kg}, 9 \mu \mathrm{g} / \mathrm{kg}$ ) Q2W were given to patients on chemotherapy, and compared with the activity of a fixed weekly dose (40000) of rHuEpo alpha. $60000 \mathrm{U}$ weekly could be used if hemoglobin increase was $<1 \mathrm{~g} / \mathrm{dL}$. The study showed that darbepoetin Q2W is as effective as rHuEpo QW, and doses of darbepoetin higher than $5 \mu \mathrm{g} / \mathrm{kg}$ do not increase the response. The feasibility of $\mathrm{Q} 2 \mathrm{~W}$ approach was confirmed by Patton and colleagues (2004) in a retrospective observational cohort study in which patients with chemotherapy-induced anemia received darbepoetin $100 \mu \mathrm{g} /$ $\mathrm{kg}$ QW, darbepoetin $200 \mu \mathrm{g} / \mathrm{kg}$ Q2W or rHuEpo (40 $000 \mathrm{U}$ QW), and by other authors (Schwartzberg et al 2004; Senecal et al 2005; Waltzman et al 2005).

Herrington and colleagues (2005) derived data from 1444 patients treated with darbepoetin alpha and 1341 with epoetin alpha. The most common initial dosages were $200 \mu \mathrm{g}$ Q2W for darbepoetin alpha (61\%), and $40000 \mathrm{U}$ QW epoetin alpha (72\%). The dosage was escalated for $22 \%$ of darbepoetin alpha recipients and $23 \%$ of epoetin alpha recipients at a median of six weeks after the initial dose. The mean change from baseline in hemoglobin concentration after 12 weeks of therapy was similar for both groups, as well as the percent of patients receiving red-blood-cell transfusions during treatment.

\section{Other schedules}

The possibility to further prolong the interval between administrations of darbepoetin in patients with cancer chemotherapy-induced anemia has also been explored. Kotasek and colleagues (2003), in a dose finding (from $4.5 \mu \mathrm{g} / \mathrm{kg}$ to $15 \mu \mathrm{g} / \mathrm{kg}$ by $2.5 \mu \mathrm{g} / \mathrm{kg}$ steps) placebo-controlled study, observed that at all doses given darbepoetin Q3W reduced transfusion requirements compared with placebo, and hemoglobin increase was dose-dependent, with an increase $\geq 1 \mathrm{~g} / \mathrm{dL}$ at doses of $6.75 \mathrm{mg} / \mathrm{kg}$ or greater. Fact-F fatigue score also improved with increasing hemoglobin concentration ( $\mathrm{p}=0.0023$ ), and safety profile was comparable in darbepoetin- and placebo-treated patients.

Glaspy and coworkers (2005) studied whether timing in respect to chemotherapy influences efficacy of darbepoetin Q3W. A dose of $6.75 \mu \mathrm{g} / \mathrm{kg}$ Q3W was administered synchronously (starting on chemotherapy day 1, patients 38) or asynchronously (starting on chemotherapy day 15, patients 43) with concurrent chemotherapy Q3W (platinum- and nonplatinum-based regimens) in patients with nonmyeloid malignancies ( $40 \%$ breast cancer). Primary endpoints were mean change in hemoglobin after 6 weeks from baseline and proportion of patients with hemoglobin increase from baseline were $1 \mathrm{~g} / \mathrm{dL}$. Secondary endpoints at the entire treatment period ( 16 weeks) were the proportion of patients with hemoglobin increase of hemoglobin $>2 \mathrm{~g} /$ $\mathrm{dL}$ or a level of $>12 \mathrm{~g} / \mathrm{dL}$ in the absence of $\mathrm{RBC}$ transfusion, time to erythropoietic response, proportion of patients who had a RBC transfusion from week 5 to end of treatment. The overall erythropoietic response was $74 \%$, and there was no difference between groups in the proportion of patients who achieved an increase in hemoglobin equal to or $>1 \mathrm{~g} /$ $\mathrm{dL}$, and time to erythropoietic response. Only $19 \%$ of patients required transfusion support. These results seem to be comparable with those obtained with darbepoetin QW administration. Two data suggest that the binding to receptor plays a role in the clearance of EPS in patients with chemotherapy-induced anemia: a) pharmacokinetic analysis 
carried out in a subset of patients indicated that endogenous erythropoietin concentration increases and lasts for approximately 1 week following chemotherapy administration; b) synchronous administration of darbepoetin alpha was associated with a 1.3-fold increase in the darbepoetin alpha area-under-the-curve compared with asynchronous administration. The feasibility of the Q3W schedule has been confirmed by Boccia and colleagues (2006)

A direct comparison between fixed $500 \mu \mathrm{g}$ Q3 W at fixed dose and $2.25 \mu \mathrm{g} / \mathrm{kg}$ QW was carried out by Canon and colleagues (2006) in a non inferiority study active-controlled phase III study, in patients with nonmyeloid malignancies. The incidence of transfusion was $19 \%$ of 353 patients in the group treated with $500 \mathrm{mg} \mathrm{Q} 3 \mathrm{~W}$ and $28 \%$ of 352 patient in the QW group. The target hemoglobin level was reached in a similar proportion of patients and increase in FACT-F score was also superimposable, without differences in toxicity.

An Q4W administration is probably possible using an adequate dosing of darbepoetin (Smith et al 2003). A hyperglycosylated analog of darbepoetin (AMG 114) with longer half life is currently in phase I clinical study.

\section{Conclusions}

Anemia is a common, underestimated and undertreated complication of cancer, especially in patients treated with chemotherapy. Provided that other factors, especially iron, are in sufficient amount to support their activity, EPS offer a simple, effective and generally safe treatment of anemia. The targets of this treatment should be: a) reduction or, possibly, elimination of transfusion support (therefore the beginning of treatment should not be delayed if the patient's hemoglobin levels is $10-11 \mathrm{~g} / \mathrm{dL}$; b) an adequate hemoglobin level (12-13 g/dL) that also would also improve QoL could be improved in patients with cancer, but avoiding higher values that could expose the patient to thromboembolic complication. The guidelines released by EORTC, NCCN, and ASCO are useful tools for these purposes.

From the large amount of data available in the literature it can be concluded that darbepoetin is as effective as rHuEpo ( $60 \%$ to $80 \%$ of patients respond to therapy) in stimulating erythropoiesis in patients with cancer. Pharmakokinetic characteristics make darbepoetin ideal for a reduced frequency of administration and more convenient for the patient by adjusting dosage and frequency to reach and maintain the target hemoglobin level. In consideration that chemotherapy is most commonly given every three week, a supplemental Biologics License Application has been submitted by the producer to the Food and Drug Administration for Q3W administration. The European Agency (EMEA) has granted darbepoetin approval for extended dosing once every three weeks interval in the treatment of cancer chemotherapy-induced anemia in 2004. In this setting there is no evidence that $500 \mu \mathrm{g}$ are more effective than $300 \mu \mathrm{g}$ in the Q3W schedule because a direct comparison of these doses is not available.

Less frequent dosing of rHuEpo, either alpha or beta, than 3 times per week proved to be effective, and adequate dosing could make the Q3W interval possible even with these erythropoietic agents.

The preliminary data of efficacy of the new pegylated Epo beta (Continuous Erythropoiesis Stimulating Activity - CERA) (Osterborg et al 2004) in a Q3W administration, and the pharmacokinetics of hematide, confirm the trend toward a reduced frequency of administration of erythropoietic proteins. The development of drugs targeting the hypoxia-inducible factor through the inactivation of the degradation enzyme prolyl-4-hydroxylase and with different (oral) route of administration are underway and could offer new perspectives in the control of anemia of cancer patients.

\section{Disclosures}

Alberto Grossi is consultant for Shire Italia.

\section{References}

Alessandrino EP, Amadori S, Barosi G, et al. 2002. Evidence- and consensus-based practice guidelines for the therapy of primary myelodysplastic syndromes. A statement from the Italian Society of Hematology. Haematologica, 87:1286-306.

Arcasoy MO, Amin K, Chou SC, et al. 2005. Erythropoietin and erythropoietin receptor expression in head and neck cancer: relationship to tumor hypoxia. Clin Cancer Res, 11:20-7.

Auerbach M, Ballard H, Trout JR, et al. 2004. Intravenous iron optimizes the response to recombinant human erythropoietin in cancer patients with chemotherapy-related anemia: a multicenter, open-label, randomized trial. J Clin Oncol, 22:1301-7.

Balleari E, Rossi E, Clavio M, et al. 2006. Erythropoietin plus granulocyte colony-stimulating factor is better than erythropoietin alone to treat anemia in low-risk myelodysplastic syndromes: results from a randomized single-centre study. Ann Hematol, 85:174-80.

Beguin Y, Verna M, Loo M, et al. 1992. Erythropoiesis in multiple myeloma: defective red cell production due to inappropriate erythropoietin production. Br J Haematol, 82:648-53.

Beguin Y. 1995. Erythropoiesis and erythropoietin in multiple myeloma. Leuk Lymphoma, 18:412-21.

Boccia R, Malik IA, Raja V, et al. 2006. Darbepoetin alpha administered every three weeks is effective for the treatment of chemotherapyinduced anemia. Oncologist, 11:4:409-17.

Bohlius J, Langensiepen S, Schwarzer G, et al. 2005. Recombinant human erythropoietin and overall survival in cancer patients: results of a comprehensive meta-analysis. J Natl Cancer Inst, 97:489-98. 
Bohlius J, Wilson J, Seidenfeld J, et al. 2006. Erythropoietin or darbepoetin for patients with cancer. Cochrane Database Syst Rev, 3:CD003407.

Bokemeyer C, Aapro MS, Courdi A et al. 2004. EORTC guidelines for the use of erythropoietic proteins in anaemic patients with cancer. Eur J Cancer, 40:2201-16.

Bren A, Kandus A, Varl J, et al. 2002. A comparison between epoetin omega and epoetin alpha in the correction of anemia in hemodialysis patients: a prospective, controlled crossover study, Artif Organs, 26:917.

Canon JL, Vansteenkiste J, György Bodoky G, et al. 2006. Randomized, double-blind, active-controlled trial of every-3-week darbepoetin alpha for the treatment of chemotherapy-induced anemia. $J$ Natl Cancer Inst, 98:273-84.

Cazzola M, Beguin Y, Kloczko J, et al. 2003. Once-weekly epoetin beta is highly effective in treating anaemic patients with lymphoproliferative malignancy and defective endogenous erythropoietin production. $\mathrm{Br}$ J Haematol, 122:386-93.

Cella D. 1997. The Functional Assessment of Cancer Therapy-Anemia (FACT-An) Scale: a new tool for the assessment of outcomes in cancer anemia and fatigue. Semin Hematol, 34(Suppl.2):13-19.

Chang J, Couture F, Young S, et al. 2005. Weekly epoetin alpha maintains hemoglobin, improves quality of life, and reduces transfusion in breast cancer patients receiving chemotherapy. J Clin Oncol, 23:2597-605.

Cheson BD, Greenberg PL, Bennett JM, et al. 2006. Clinical application and proposal for modification of the International Working Group (IWG) response criteria in myelodysplasia. Blood, 108:419-25.

Deicher R, Horl WH. 2004. Differentiating factors between erythropoiesisstimulating agents: a guide to selection for anaemia of chronic kidney disease. Drugs, 64:499-509.

Egrie JC, Browne JK. 2001. Development and characterization of novel erythropoiesis stimulating protein (NESP). Br J Cancer, 84(Suppl.1):3-10.

Elliott S, Busse L, Bass ME, et al. 2006. Anti-Epo receptor antibodies do not predict Epo receptor expression. Blood, 107:1892-5.

Elliott S, Egrie J, Browne J, et al. 2004. Control of rHuEPO biological activity: the role of carbohydrate. Exp Hematol, 32:1146-55.

Gabrilove JL, Cleeland CS, Livingstone RB, et al. 2001. Clinical evaluation of once-weekly dosing of epoetin alpha in chemotherapy patients: improvements in hemoglobin and quality of life are similar to threetimes-weekly dosing. J Clin Oncol, 19:2875-82.

Glaspy J, Henry D, Patel R, et al. 2005. Effects of chemotherapy on endogenous erythropoietin levels and the pharmacokinetics and erythropoietic response of darbepoetin alpha: a randomised clinical trial of synchronous versus asynchronous dosing of darbepoetin alpha, Eur J Cancer, 41:1140-9.

Glaspy JA, Jadeja JS, Justice G, et al. 2002. Darbepoetin alpha given every 1 or 2 weeks alleviates anaemia associated with cancer chemotherapy. Br J Cancer, 87:268-76.

Harper P, Littlewood T. 2005. Anemia of cancer: impact on patient fatigue and long-term outcome. Oncology, 69(suppl 2):2-7.

Heatherington AC, Schuller J, Mercer AJ. 2001. Pharmakokinetics of novel erythropoiesis stimulating protein (NESP) in cance patients: preliminary report, Br J Cancer, 84(suppl.1):11-16.

Hedenus M, Adriansson M, San Miguel J, et al. 2003. Efficacy and safety of darbepoetin alpha in anaemic patients with lymphoproliferative malignancies: a randomized, double-blind, placebo-controlled study. Br J Haematol, 122:394-403.

Hellstrom-Lindberg E, Ahlgren T, Beguin Y, et al. 1998. Treatment of anemia in myelodysplastic syndromes with granulocyte colonystimulating factor plus erythropoietin: results from a randomized phase II study and long-term follow-up of 71 patients. Blood, 92:68-75.

Henke M, Laszig R, Rube C, et al. 2003. Erythropoietin to treat head and neck cancer patients with anemia undergoing radiotherapy: randomised, double-blind, placebo controlled trial. Lancet, 362:1255-60.
Henry DH, Gordan L, Charu V, et al. 2006. Randomized, open-label comparison of epoetin alpha extended dosing (80000 U Q2W) vs weekly dosing (40000 U QW) in patients with chemotherapy-induced anemia. Curr Med Res Opin, 22:1403-13.

Herrington JD, Davidson SL, Tomita DK, et al. 2005. Utilization of darbepoetin alpha and epoetin alpha for chemotherapy-induced anemia. Am J Health Syst Pharm, 62:54-62.

[ICSG] Italian Cooperative Study Group for rHuEpo in Myelodysplastic Syndromes. 1998. A randomized double-blind placebo-controlled study with subcutaneous recombinant human erythropoietin in patients with low-risk myelodysplastic syndromes. Br J Haematol, 103:10704

Kotasek D,Steger G, Faught W, et al. 2003. Darbepoetin alpha administered every 3 weeks alleviated anaemia in patients with solid tumors receiving chemotherapy; results of a double-blind, placebo-conrolled, randomised study. Eur J Cancer, 39:2026-34.

Leyland-Jones B; BEST Investigators and Study Group. 2003. Breast cancer trial with erythropoietin terminated unexpectedly. Lancet Oncol, 4:459-60.

Littlewood TJ, Bajetta E, Nortier JW, et al. 2001. Epoetin alpha study group. Effects of epoetin alpha on hematologic parameters and quality of life in cancer patients receiving nonplatinum chemotherapy: results of a randomized, double-blind, placebo-controlled trial. J Clin Oncol, 19:2865-74.

Littlewood TJ, Kallich JD, San Miguel J, et al. 2006. Efficacy of darbepoetin alpha in alleviating fatigue and the effect of fatigue on quality of life in anemic patients with lymphoproliferative malignancies. J Pain Symptom Manage, 3:317-25.

Littlewood TJ, Zagari M, Pallister C, et al. 2003. Baseline and early treatment factors are not clinically useful for predictingindividual response to erythropoietin in anemic cancer patients. Oncologist, 8:99107.

Ludwig H, Van Belle S, Barrett-Lee P, et al. 2004. The European Cancer Anaemia Survey (ECAS): a large, multinational, prospective survey defining the prevalence, incidence, and treatment of anaemia in cancer patients. Eur J Cancer, 40:2293-306

Mannone L, Gardin C, Quarre MC, et al. 2006. High-dose darbepoetin alpha in the treatment of anaemia of lower risk myelodysplastic syndrome results of a phase II study. Br J Haematol, 133:513-19.

Musto P, Lanza F, Balleari E, et al. 2005. Darbepoetin alpha for the treatment of anaemia in low-intermediate risk myelodysplastic syndromes. Br J Haematol, 128:204-9.

[NCCN] National Comprehensive Cancer Network. 2006. Clinical practice guidelines in oncology, v.2.2006. Cancer and treatment-related anemia [online]. Accessed on 25 Sept 2006. URL: http:/www.enccn.com/ professionals/physician_gls/PDF/anemia.pdf.

Osterborg A, Brandberg Y, Molostova V, et al. 2002. Randomized, doubleblind, placebo-controlled trial of recombinant human erythropoietin, epoetin Beta, in hematologic malignancies. J Clin Oncol, 20:248694.

Osterborg A, Hellmann A, Juan Luis Steegmann JL, et al. 2004. CERA (Continuous Erythropoietin Receptor Activator): Dose-response trial of subcutaneous (SC) administration once every 3 weeks (Q3W) to patients with aggressive non-Hodgkin's lymphoma and anemia receiving chemotherapy [abstract]. $46^{\text {th }}$ meeting of the American Society of Hematology, December 4-7, San Diego, CA. Blood, 104:4225.

Patton J, Reeves T, Wallace J. 2004. Effectiveness of Darbepoetin alpha versus Epoetin alpha in patients with chemotherapy-induced anemia treated in clinical practice. Oncologist, 9:451-8.

Patton JF, Sullivan T, Mun Y, et al. 2005. A retrospective cohort study to assess the impact of therapeutic substitution of darbepoetin alpha for epoetin alpha in anemic patients with myelodysplastic syndrome. $J$ Support Oncol, 3:419-26. 
Rizzo JD, Lichtin AE, Woolf SH, et al. 2002. Use of erythropoietin in patients with cancer: evidence-based clinical practice guidelines of the American Society of Clinical Oncology and the American Society of Hematology. J Clin Oncol, 20:4083-107.

Schwartzberg LS, Yee LK, Senecal FM, et al. 2004. A randomized comparison of every-2-week darbepoetin alpha and weekly epoetin alpha for the treatment of chemotherapy-induced anemia in patients with breast, lung, or gynecologic cancer. Oncologist, 9:696-707.

Senecal FM, Yee L, Gabrail N, et al. 2005. Treatment of chemotherapyinduced anemia in breast cancer: results of a randomized controlled trial of darbepoetin alpha 200 microg every 2 weeks versus epoetin alpha 40,000 U weekly. Clin Breast Cancer, 6:446-54.

Shasha D, George MJ, Louis B, et al. 2003. Once-weekly dosing of epoetinalpha increases hemoglobin and improves quality of life in anemic cancer patients receiving radiation therapy either concomitantly or sequentially with chemotherapy. Cancer, 98:1072-9.

Smith RE Jr, Jaiyesimi IA, Meza LA, et al. 2001. Novel erythropoiesis stimulating protein (NESP) for the treatment of anaemia of chronic disease associated with cancer. Br J Cancer, 84(Suppl.1):24-30.

Smith RE Jr, Tchekmedyian NS, Chan D, et al. 2003. A dose- and schedulefinding study of darbepoetin alpha for the treatment of chronic anaemia of cancer. Br J Cancer, 88:1851-8.
Stead RB, Lambert J, Wessels D, et al. 2006. Evaluation of the safety and pharmacodynamics of Hematide, a novel erythropoietic agent, in a phase 1, double-blind, placebo-controlled,dose-escalation study in healthy volunteers. Blood, 108:1830-4.

Terpos E, Mougiou A, Kouraklis A; The Greek MDS Study Group. 2003. Prolonged administration of erythropoietin increases erythroid response rate in myelodysplastic syndromes: a phase II trial in 281 patients. BrJ Haematol, 118:174-80.

Vadhan-Raj S, Mirtsching B, Charu V, et al. 2003. Assessment of hematologic effects and fatigue in cancer patients with chemotherapyinduced anemia given darbepoetin alpha every two weeks. $J$ Support Oncol, 1:131-8.

Vansteenkiste J, Pirker R, Massuti B, et al. 2002. Double-blind, placebocontrolled, randomized phase iii trial of darbepoetin alpha in lung cancer patients receiving chemotherapy. J Natl Cancer Inst, 94:1211-20.

Waltzman R, Croot C, Justice GR, et al. 2005. Randomized comparison of epoetin alpha (40,000 U weekly) and darbepoetin alpha (200 microg every 2 weeks) in anemic patients with cancer receiving chemotherapy. Oncologist, 10:642-50.

Witzig TE, Silberstein PT, Loprinzi CL, et al. 2005. Phase III, randomized, double-blind study of epoetin alpha compared with placebo in anemic patients receiving chemotherapy. J Clin Oncol, 23:2606-17. 
